Original article

\title{
Comparison of the efficacy of two laser types in healing of full-thickness wound: an experimental study
}

\author{
Hesham Galal Mahran \\ Cairo University, Giza, Egypt
}

Received 3 October 2018, Revised 5 June 2020, Accepted 15 September 2020

(C) 2018, Mahran H.G.

C 2018, Russian Open Medical Journal

Abstract: The aim of the study - To investigate the effectiveness of pulsed laser with high intensity and laser with low intensity on a fullthickness wound in rats and to compare the effects of both laser types.

Material and Methods - Forty-five adult male rats were utilized in the present study. After anesthesia, wound of five $\mathrm{cm}^{2}$ was produced on dorsal aspect in each rat; then, the rats were randomly classified into three groups as follows: high power pulsating laser group (A) which received Nd: YAG laser with $1064 \mathrm{~nm}$ wavelength, low power laser group (B) which received GaAlAs laser with $830 \mathrm{~nm}$ wavelength, and control group (C) which received no treatment. Laser lights in groups (A) and (B) were introduced at an intensity of five joules per $\mathrm{cm}^{2}$ with a total energy of 25 joules for each wound area through the use of a scanning method and at a rate of 3 sessions per week for three weeks.

Results - At the end of treatment, better wound healing in form of more wound contraction and higher healing rate was elicited in both laser groups in comparison to wound healing in the control group, and there were no significantly different effects between both laser types.

Conclusion - At the intensity of five joules $/ \mathrm{cm}^{2}$, both low-intensity and pulsating high-intensity lasers speed up the healing of the wound in rats, and there are no significant differences between their effects.

Keywords: Rats, full-thickness wound, low-intensity laser, and high-intensity laser.

Cite as Mahran HG. Comparison of the efficacy of two laser types in healing of full-thickness wound: an experimental study. Russian Open Medical Journal 2020; 9: e0418.

Correspondence to Hesham Galal Mahran. E-mail: heshammahran75@yahoo.com.

\section{Introduction}

Wound is caused from skin injury when an interruption of soft tissues [1], epithelial continuity, and underneath connective tissue occurs [2]. Uninjured skin protects the entire tissues and organs against the outside environment. Wound is healed through a tissue self-repair after trauma $[3,4]$. The process of healing is formed through three phases as follows: the inflammation phase, the granulation tissue phase, and the remodeling phase. It is a complicated process that involves an interaction among different elements and cells [5]. Treating thousands of patients with chronic wounds costs a lot of money annually [6]. The perfect closing of a wound is considered as the standard goal of treatment. Good wound management includes wound bed preparation, wound debridement, and wound closure by surgery (grafting or flaps). Not only, all these therapies need prolonged time and hard work, but also, they are cost-effective. Many therapies have been utilized for treating different types of wound, including laser therapy $[7,8]$.

The light of laser is a very special form of light. It differs from most light sources, as it is converted to specific wavelengths allowing it to be emitted in focused powerful beams. The devices of high-intensity laser therapy (HILT) have a power output that ranges from 500 to 7500 milliwatts providing more power and deeper penetration in less time and larger surface of treatment area than laser with low intensity [9]. Low-intensity laser therapy (LILT), as a near infrared laser, introduces a wavelength that ranges from 600 to 1000 nanometers and a range of power that extends from 5 to 500 milliwatts [10]. Various laser types have been studied as healing tools such as helium-neon, gallium arsenide, Nd: YAG, and gallium aluminum arsenide (GaAlAs) [11, 12]. Monochromaticity of laser wavelength is useful for efficient coupling as absorbed by chromophores at a maximal limit, leading to the improvement of biological processes $[13,14]$.

The penetrating effect of laser is indicated through laser radiation frequency and cell type to be exposed to laser radiation. A gallium aluminum arsenide unit (GaAlAs) produces a laser beam that provides deeper penetration in comparison with a laser beam with a shorter wavelength, like a beam of red light produced by a He-Ne laser as it has a more superficial effect [15]. High-intensity laser therapy (HILT) or neodymium laser: yttrium-aluminum garnet (Nd: YAG) emits light at $1064 \mathrm{~nm}$. At this wavelength, the laser beam is consumed more in the bloodstream than in the tissues, leading to deep penetration and wide diffusion into the tissue, thus producing the Nd: YAG laser main effect [16]. In recent years, HILT has been utilized in traumatology and pain therapy due to its successful applications in these areas. Unlike the particular extensive literature that confirms the effects of low-intensity laser 
therapy on healing, no specific data has been reported yet regarding the conjunction of the Nd: YAG with the healing of various wound types $[17,18]$.

The challenges in treating the full-thickness wound force us to find new, low cost, and efficient treatment with less labor. Although there are many previous studies that dealt with various types of therapeutic lasers and examined their effects on tissues and healing processes, most of those lasers were low-intensity types. The novel in our study was utilizing a pulsed high-intensity laser which was mentioned in most researches for musculoskeletal disorder cases, although no or little researches mentioned it in wound studies. Application of continuous mode of high-intensity laser on wound is contraindication and may have reverse deteriorating effect on wound healing; therefore, another novel issue to be considered in our study was the use of high-intensity laser with pulsating mode which allows high peak power to reach deep in a short period of time without any reverse effect or thermal damage. Thus, the study was designed to evaluate and compare the efficacy of uncommon used laser (pulsed high power laser; Nd: YAG) with one which was commonly used in wound (low power laser; GaAlAs) with wavelengths of $1064 \mathrm{~nm}$ and $830 \mathrm{~nm}$, respectively, and at intensity of $5 \mathrm{~J} / \mathrm{cm}^{2}$ on the full-thickness wound in rats.

\section{Material and Methods}

\section{Animals}

Forty-five albino male rats were utilized in the present study. They weighed approximately $0.150-0.250 \mathrm{~kg}$ and aged about four months when the study started. They were selected from the animal house, Faculty of Medicine, at Umm Al-Qura University. Each rat was individually placed in a separate stainless steel cage, made with a wired floor, and room environment was controlled with the atmospheric temperature being adjusted to $23-25{ }^{\square} \mathrm{C}$. The humidity was controlled to $50 \%$, and the cycle of light was controlled artificially with a 12-hour dark-light period. In the lower part of the cages, food (Purina) which was kept in a granular form and drinking water were introduced.

\section{Procedures}

Wound Surgery Model. After anesthesia, area for the wound was shaved, prepared, and disinfected (70\% alcoholic Conc.). A stamp with a size of $5 \mathrm{~cm}^{2}$ was utilized for defining a uniform area $(2.5 \times 2$ $\mathrm{cm}$ ) from the posterior aspect of each rat; then all defined skins were excised. Each wounded rat was placed in a separate cage. All surgical procedures for all rats were carried out by one researcher.

Research Design. A randomized controlled study had been designed as rats were randomly assigned into 3 equal groups.

Treatment Intervention. In group (A), wound areas of fifteen rats were exposed to high-intensity laser with pulsed radiation (Nd: YAG laser light, $1064 \mathrm{~nm}$ : ASAsrl Company, made in Italy, HIRO 3.0 model) with the following parameters: laser intensity was $5 \mathrm{~J} / \mathrm{cm}^{2}$, being applied 3 times per week for 3 weeks, through the use of scanning method, with a distance of approximately $1 \mathrm{~cm}$ above wound surface. The time of application was 15 seconds at the $1^{\text {st }}$ session and in the other sessions, the time was changed according to the shrunken wound surface area. In group (B), wound areas of fifteen rats were exposed to low-intensity laser (GAlAs laser, $830 \mathrm{~nm}$ : BTL 5000, made in the UK) with the same parameters applied in group (A) except for time of application that was approximately 5 minutes for the $1^{\text {st }}$ session and in the other sessions, the time of application was changed along with the wound area changing. In group (C), wound areas of fifteen rats were not exposed to any treatment.

Measurement. The tracing technique was utilized for estimating the wounded area of each rat as a transparent film was applied to the area in order to trace each wound boundary; then, the traced film was placed on a $1 \mathrm{~mm}$ chart sheet. The square millimeters were counted and completely transformed into square centimeters, and the wound area for each rat was recorded. Additionally, the wound contraction rate at $(\mathrm{X})$ day was calculated by the following equation: [(area of $1^{\text {st }}$ day - area of $(X)$ day) /area of the $1^{\text {st }}$ day] $\times 100$.

For each rat, wound area, as well as the rate of wound contraction, was measured at the end of each week of treatment as 3 measures provided.

\section{Statistical analysis}

After collecting data, data analysis was carried out by the SPSS (v.16) as means plus standard deviations were estimated. The data for our study was a parametric type, so comparing mean values between groups as well as within each group was achieved through the use of one-way ANOVA, as well as repeated measures, respectively. With a $p$ value less than 0.05 , the differences had been considered as statistically significant.

\section{Results}

All animals had the same type (albino type). They received the same type of food, the same caring, and the same hygiene. As regards baseline data, including age, weight, and wound surface area (almost five $\mathrm{cm}^{2}$ ), there were no significant differences among the three groups.

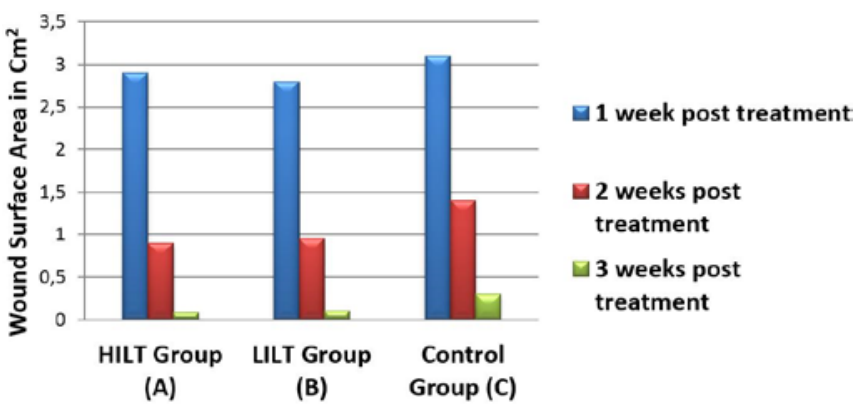

Figure 1. The mean values of the wound area for three measures in each group.

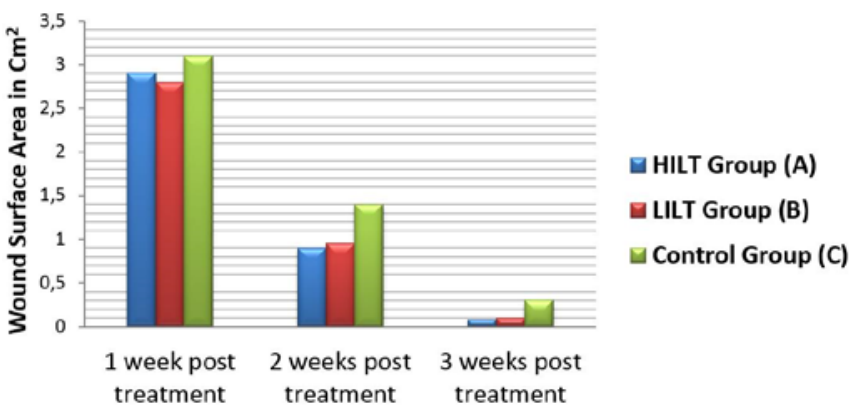

Figure 2. The mean values of the wound area between groups at each measurement time. 
Table 1. Comparisons of mean values of both wound area and healing rate between groups and within each group

\begin{tabular}{|c|c|c|c|c|c|c|c|}
\hline \multirow[b]{2}{*}{ Mean $\pm S D$} & \multicolumn{2}{|c|}{$1^{\text {st }}$ week } & \multicolumn{2}{|c|}{$2^{\text {nd }}$ week } & \multicolumn{2}{|c|}{$3^{\text {rd }}$ week } & \multirow{2}{*}{$P$-value } \\
\hline & WSA $\left(\mathrm{cm}^{2}\right)$ & R.H. (\%) & WSA $\left(\mathrm{cm}^{2}\right)$ & R.H. (\%) & WSA $\left(\mathrm{cm}^{2}\right)$ & R.H. (\%) & \\
\hline Group A (HILT) & $2.9 \pm 0.60$ & $42 \pm 15.83$ & $0.9 \pm 0.65$ & $82.4 \pm 6.7$ & $0.08 \pm .06$ & $98.4 \pm 2.2$ & 0.0001 \\
\hline Group B (LILT) & $2.8 \pm 0.81$ & $44.66 \pm 13$ & $0.95 \pm 0.61$ & $81.6 \pm 9.2$ & $0.1 \pm 0.12$ & $97.5 \pm 2.0$ & 0.0001 \\
\hline Group C (Control) & $3.1 \pm 0.77$ & $38.6 \pm 18.5$ & $1.4 \pm 0.7$ & $72.5 \pm 13$ & $0.3 \pm 0.2$ & $94 \pm 3.56$ & 0.0001 \\
\hline P-value & \multicolumn{2}{|c|}{0.52} & \multicolumn{2}{|c|}{0.038} & \multicolumn{2}{|c|}{0.048} & \\
\hline Post Hoc test & $\begin{array}{r}(A) v s .(B)=(0 \\
(A) v\end{array}$ & $\begin{array}{l}s .(\mathrm{C})=(0.19) \\
.62)\end{array}$ & $\begin{array}{r}(A) v s .(B)=(0.7 \\
(A) v s .\end{array}$ & $\begin{array}{l}(\mathrm{C})=(0.022) \\
42)\end{array}$ & $\begin{array}{r}\text { vs. }(B)=(0.60 \\
(A) v s .(C\end{array}$ & $\begin{array}{l}(\mathrm{C})=(0.00 \\
46)\end{array}$ & \\
\hline
\end{tabular}

WSA, Wound Surface Area; R.H., Rate of Healing; HILT, High-Intensity Laser Therapy; LILT. Low-Intensity Laser Therapy; (A), Group (A); (B), Group (B); (C), Group (C). (A)vs.(B) - Comparison between group (A) and group (B). (B)vs.(C) - Comparison between group (B) and group (C). (A)vs.(C) - Comparison between group $(A)$ and group $(C)$.

The results in Table 1 and Figure 1 indicate a highly significant increase in wound healing throughout three measures within each group as data analysis was performed through the use of repeated-measures ANOVA and $p=0.0001$ between measures.

After $1^{\text {st }}$ week of treatment as shown in Table 1 and Figure 2, the mean values of both wound area and healing rate in laser group (A) were $2.9 \pm 0.60 \mathrm{~cm}^{2}$ and $42 \pm 15.83 \%$, respectively; in laser group (B) were $2.8 \pm 0.81 \mathrm{~cm}^{2}$ and $44.66 \pm 13 \%$, respectively; and in control group (C) were $3.1 \pm 0.77 \mathrm{~cm}^{2}$ and $38.6 \pm 18.5 \%$, respectively. One-way ANOVA analysis of the results of the $1^{\text {st }}$ week revealed that there were no statistically significant differences among groups as $p$ value $=0.52$. Furthermore, there were no significant differences in the mean values of either WSA or healing rate between every 2 groups when data were further analyzed by posthoc test as $p$ value is more than 0.05 for all.

After $2^{\text {nd }}$ week of treatment as also shown in Table 1 and Figure 2, the mean values of both wound area and healing rate in laser group (A) were $0.9 \pm 0.65 \mathrm{~cm}^{2}$ and $82.4 \pm 6.7 \%$, respectively; in laser group (B) were $0.95 \pm 0.61 \mathrm{~cm}^{2}$ and $81.6 \pm 9.2 \%$, respectively; and in control group (C) were $1.4 \pm 0.7 \mathrm{~cm}^{2}$ and $72.5 \pm 13 \%$, respectively. Upon analysis of data, there were significant differences among the three groups ( $p$-value $=0.038)$. More data analysis elicited that there were no significant differences in mean values of either wound area or healing rate between laser group (A) and laser group (B) as $p$ value $=0.71$, while there were statistically significant differences for laser group (A) versus control group (C) and laser group (B) versus control group (C) as $p$ values equal 0.042 and 0.022 , respectively.

After $3^{\text {rd }}$ week of treatment as shown in Table 1 and Figure 2, mean values of both wound area and healing rate in laser group (A) were $0.08 \pm .06 \mathrm{~cm}^{2}$ and $98.4 \pm 2.2 \%$, respectively; in laser group (B) were $0.1 \pm 0.12 \mathrm{~cm}^{2}$ and $97.5 \pm 2 \%$, respectively; and in control group (C) were $0.3 \pm 0.2 \mathrm{~cm}^{2}$ and about $94.0 \pm 3.56 \%$, respectively. Analysis of data provided that there were significant differences among all groups as $p$-value $=0.048$. Further data analysis indicated that there were no significant differences in mean values of either wound area or healing rate between laser group $(A)$ and laser group (B) as $p$-value $=0.60$, while there were significant differences for group (A) versus group (C) and group (B) versus group (C) as $p$ values equal 0.046 and 0.003 , respectively.

\section{Discussion}

In the present study, excisional wounds in rats were performed in order to investigate the efficacy of using pulsed $\mathrm{Nd}$ : YAG laser light with $1064 \mathrm{~nm}$ as a high-intensity laser and GaAlAs laser with $830 \mathrm{~nm}$ as a low-intensity laser at the same intensity level $\left(5 \mathrm{j} / \mathrm{cm}^{2}\right)$ and to compare both laser effects. Our study demonstrated that both laser types at intensity of 5 joules $/ \mathrm{cm}^{2}$ improved the healing of wound after three weeks of treatment. There were significant shrinkages of wound surface areas and increase of healing rates in groups (A) and (B) in comparison with those in group (C). On the other hand, when comparing both laser groups (A) and (B), the researcher found no significant difference between two lasers regarding their healing effect. These results agreed with some previously published studies which found that the laser healing effect may be related to its bio-modulatory effects that rely on a theory stating that energy of the photon is ingested by photo acceptor elements, and then the energy is turned to chemical energy type inside the cells. Cytochrome $\mathrm{m}$. oxidase accepts photons and enhances alteration in the mitochondrial redox resulting in the alteration of the ions across the membrane of mitochondria as well as an increase in ATP formation [19]. Additionally, intracellular calcium (Ca2+) increases, resulting in hastening DNA and RNA formation and activating the series of intracellular indicators [20].

All previous events facilitate DNA duplication, protein formation, oxidative stress regulation, and different cytokines modulation $[21,22]$. These all lead to producing various types of cellular bio-modulations which are involved in tissues build-up [23]. These bio-modulations include fibroblast mitosis [24], angiogenesis $[25,26]$, cytokines activity changes, and fibroblasts transformation into myofibroblasts [24].

Recent studies demonstrated that the production of growth factors was significantly altered in wounds exposed to laser therapy of low intensity. These recent studies stated that LILT facilitates wound healing by influencing relevant growth factors level, facilitating the division and migration of cells, and enhancing the extracellular matrix formation. LILT promotes healing of the wound by reducing inflammatory exudation, enhancing wound shrinking, and preventing infection in different healing phases [27].

Valdinaldo et al. suggested that laser light provides regulation of inflammation and accelerates biological processes which lead to wound healing. Low-intensity laser enhances collagen deposition and promotes new blood vessel formation [28].

As per Fabiana et al., the laser doses ranging between 3 and 6 $\mathrm{J} / \mathrm{cm}^{2}$ appear to be more effective, while doses over 10 joules $/ \mathrm{cm}^{2}$ may have dangerous effects. Moreover, the wavelengths ranging between 632.8 and 1000 nanometers have more effective results in wound healing [29]. Pulsed Nd: YAG laser light has been confirmed as an effective and beneficial light in treating different diseases of the musculoskeletal system as it is believed to have anti-inflammatory, anti-edema, and sedative effects [30]. On the other hand, its effects on tissue regeneration have not been covered in recent studies $[31,32]$. The pulsed Nd: YAG laser is a 
high power laser that utilizes a wavelength emission of $1064 \mathrm{~nm}$ which is weakly absorbed by cell and tissue chromophores leading to perfect penetration capacity and ability to reach deep tissues. Furthermore, the photothermal impaction is safety and comfort due to an ability to modulate to pulse mode [33].

Pulsed Nd: YAG laser accelerates the formation of extracellular matrix molecules in connective tissue cells [34-35]. This kind of high intensity with limited time exposure prevents the accumulation of heat in the tissues as happens through the use of Nd: YAG laser with continuous emission. This allows a greater propagation of the radiation in the tissues with a very low damage risk, resulting in remedying deep tissue and structures. Photostimulation enhances the repair of tissues by increasing the collagen number and overall connective tissues [36].

Some studies demonstrated that HILT seems to be better than LILT in the healing of wounds because of its higher intensity and also due to the increased depth reached by the laser [33]. A.A. Ebid et al. found that HILT is a useful treatment for promoting fullthickness wound shrinkage as the study indicated that there are more regeneration and better healing in laser group compared to the control group. This confirms the effectiveness of pulsed laser light with high intensity in the healing of wound [37]. Furthermore, the same authors evaluated the effect of high-intensity laser on chronic foot ulcers in diabetic patients and they found that, in comparison to the control group, there is a significant increase in wound contraction in the laser group [38]. In agreement with the findings of previous studies, our findings support the hypothesis that wound healing can be accelerated through the use of a lowintensity laser $(830 \mathrm{~nm})$ or pulsed high-intensity laser $(1064 \mathrm{~nm})$ at intensity of $5 \mathrm{~J} / \mathrm{cm}^{2}$, and both healing tools are safe and effective for the treatment of the full-thickness wound.

\section{Conclusion}

At the intensity of five joules $/ \mathrm{cm}^{2}$, both low-intensity and pulsating high-intensity lasers speed up the healing of the wound in rats, and both laser types showed no different effects at that intensity level.

\section{Conflicts of Interest}

The author declares no conflicts of interest.

\section{Funding}

This research did not receive any specific grant from any funding agencies.

\section{Ethical Approval}

All procedures regarding the care and use of animals performed in the study were in accordance with the ethical standards of Faculty of Medicine, Umm Al-Qura University, Mecca, Saudi Arabia. In addition, all aspects and protocol of the study were approved by the ethical committee of the Faculty of Physical Therapy, Cairo University, Egypt.

\section{References}

1. Gothai S, Arulselvan P, Tan WS, Fakurazi S. Wound healing properties of ethyl acetate fraction of Moringa oleifera in normal human dermal fibroblasts. J Intercult Ethnopharmacol 2016; 5(1): 1-6. https://doi.org/10.5455/jice.20160201055629.

2. Wounds: Biology and Management. Leaper DJ, Harding KG, eds. 1st ed. Oxford, Great Britain: Oxford University Press. 1998; $210 \mathrm{p}$.
3. Nguyen DT, Orgill DP, Murphy GF. The pathophysiologic basis for wound healing and cutaneous regeneration. In: Biomaterials for Treating Skin Loss. Orgill DP, Blanco C, eds. Wood head Publishing. 2009; 25-57. https://doi.org/10.1533/9781845695545.1.25.

4. Rieger S, Zhao H, Martin P, Abe K, Lisse TS. The role of nuclear hormone receptors in cutaneous wound repair. Cell Biochem Funct 2015; 33(1): 1-13. https://doi.org/10.1002/cbf.3086.

5. Singer AJ, Clark RA. Cutaneous wound healing. N Engl J Med 1999; 341(10): 738-746. https://doi.org/10.1056/nejm199909023411006.

6. Sen CK, Gordillo GM, Roy S, Kirsner R, Lambert L, Hunt TK, et al. Human skin wounds: a major and snowballing threat to public health and the economy. Wound Repair Regen 2009; 17(6): 763-771. https://doi.org/10.1111/i.1524-475x.2009.00543.x.

7. Monici $M$, Cialdai F, Fusi F, Romano G, Pratesi R. Effects of pulsed $\mathrm{Nd}$ YYAG laser at molecular and cellular level. A study on the basis of Hilterapia. Energy for Health. 2009; (3): 26-33. https://www.asalaser.com/en/research-training/asa-researchlibrary/effects-pulsed-ndyag-laser-molecular-and-cellular-level-studybasis-hilterapia.

8. The science of photobiology. Smith K, ed. 2nd ed. New York, USA: Springer US. 1989; VIII, 426 p. https://doi.org/10.1007/978-1-46158061-4.

9. Maiya AG, Kumar P, Nayak S. Photo-stimulatory effect of low energy helium-neon laser irradiation on excisional diabetic wound healing dynamics in Wistar rats. Indian J Dermatol 2009; 54(4): 323-329. https://doi.org/10.4103/0019-5154.57606.

10. Castano AP, Dai T, Yaroslavsky I, Cohen R, Apruzzese WA, Smotrich $\mathrm{MH}$, et al. Low-level laser therapy for zymosan-induced arthritis in rats: Importance of illumination time. Lasers Surg Med 2007; 39(6): 543550. https://doi.org/10.1002/Ism.20516.

11. Jenkins PA, Carroll JD. How to report low-level laser therapy (LLLT)/photomedicine dose and beam parameters in clinical and laboratory studies. Photomed Laser Surg 2011; 29(12): 785-787. https://doi.org/10.1089/pho.2011.9895.

12. Bayat M, Vasheghani MM, Razavi N. Effect of low-level helium-neon laser therapy on the healing of third-degree burns in rats. J Photochem $\begin{array}{llll}\text { Photobiol } & \text { B 2006; 83(2): }\end{array}$ https://doi.org/10.1016/j.jphotobiol.2005.12.009.

13. Pessoa ES, Melhado RM, Theodoro LH, Garcia VG. A histologic assessment of the influence of low-intensity laser therapy on wound healing in steroid-treated animals. Photomed Laser Surg 2004; 22(3): 199-204. https://doi.org/10.1089/1549541041438533.

14. Kreisler M, Christoffers AB, Al-Haj H, Willershausen B, d'Hoedt B. Low level $809-\mathrm{nm}$ diode laser-induced in vitro stimulation of the proliferation of human gingival fibroblasts. Lasers Surg Med 2002; 30(5): 365-369. https://doi.org/10.1002//sm.10060.

15. Al-Henhena N, Mahmood AA, Al-magrami A, Nor Syuhada AB, Zahra $A A$, Summaya $M D$, et al. Histological study of wound healing potential by ethanol leaf extract of Strobilanthes crispus in rats. J Med Plant Res 2011; 5(16): 3660-3666. https://academicjournals.Org/journal/JMPR/article-full-textpdf/17D81E520829.

16. Ejaz $\mathrm{S}$, Ashraf $\mathrm{M}$, Nawaz $\mathrm{M}$, Lim CW. Total particulate matter and wound healing: an in vivo study with histological insights. Biomed Environ Sci 2009; 22(4): 278-287. https://doi.org/10.1016/s08953988(09)60057-x.

17. Braiman-Wiksman L, Solomonik I, Spira R, Tennenbaum T. Novel insights into wound healing sequence of events. Toxicol Pathol 2007; 35(6): 767-779. https://doi.org/10.1080/01926230701584189.

18. Liang X, Bhattacharya S, Bajaj G, Guha G, Wang Z, Jang HS, et al. Delayed cutaneous wound healing and aberrant expression of hair follicle stem cell markers in mice selectively lacking Ctip2 in epidermis. $\begin{array}{llll}\text { PLOS One 2012; } & \text { 7(2): }\end{array}$ https://doi.org/10.1371/journal.pone.0029999. 
19. Houreld NN. Shedding light on a new treatment for diabetic wound healing: a review on phototherapy. The Scientific World Journal 2014; 2014: 398412. https://doi.org/10.1155/2014/398412.

20. Karu T. Primary and secondary mechanisms of action of visible to nearIR radiation on cells. J Photochem Photobiol B 1999; 49(1): 1-17. https://doi.org/10.1016/s1011-1344(98)00219-x.

21. Silveira PC, Silva LA, Fraga DB, Freitas TP, Streck EL, Pinho R. Evaluation of mitochondrial respiratory chain activity in muscle healing by lowlevel laser therapy. J Photochem Photobiol B 2009; 95(2): 89-92. https://doi.org/10.1016/i.jphotobiol.2009.01.004.

22. Alves AC, Vieira R, Leal-Junior $E$, dos Santos $S$, Ligeiro AP, Albertini R, et al. Effect of low-level laser therapy on the expression of inflammatory mediators and on neutrophils and macrophages in acute joint inflammation. Arthritis Res Ther 2013; 15(5): R116. https://doi.org/10.1186/ar4296.

23. Ribeiro MA, Albuquerque RL Jr, Ramalho LM, Pinheiro AL, Bonjardim LR, Da Cunha SS. Immunohistochemical assessment of myofibroblasts and lymphoid cells during wound healing in rats subjected to laser photobiomodulation at $660 \mathrm{~nm}$. Photomed Laser Surg 2009; 27(1): 4955. https://doi.org/10.1089/pho.2007.2215.

24. Bates-Jensen BM. The Pressure Sore Status Tool a few thousand assessments later. Adv Wound Care 1997; 10(5): 65-73. https://pubmed.ncbi.nlm.nih.gov/9362584/.

25. Bayat M, Azari A, Golmohammadi MG. Effects of 780-nm low-level laser therapy with a pulsed gallium aluminum arsenide laser on the healing of a surgically induced open skin wound of rat. Photomed Laser Surg 2010; 28(4): 465-470. https://doi.org/10.1089/pho.2008.2450.

26. Fukuda TY, Tanji MM, Jesus JF, Sato MN, Duarte AJ, Plapler H. Single session to infrared low level diode laser on TNF-alpha and IL-6 cytokines release by mononuclear spleen cells in mice: a pilot study. Lasers Surg Med 2010; 42(6): 584-588. https://doi.org/10.1002/Ism.20949.

27. Ma H, Li $Y$, Chen $H$, Kang M, Liu TC Effects of Low-Intensity Laser Irradiation on Wound Healing in Diabetic Rats. International Journal of Photoenergy. 2012; 2012: 838496 https://doi.org/10.1155/2012/838496.

28. Melo VA, Anjos DC, Albuquerque Júnior R, Melo DB, Carvalho FU. Effect of low level laser on sutured wound healing in rats. Acta Cir Bras 2011; 26(2): 129-134. https://doi.org/10.1590/s010286502011000200010 .

29. Andrade Fdo S, Clark RM, Ferreira ML. Effects of low-level laser therapy on wound healing. Rev Col Bras Cir 2014; 41(2): 129-133. https://doi.org/10.1590/s0100-69912014000200010.

30. 30. Zati A, Fortuna D, Valent A, Filippi MV, Bilotta TW. High Intensity Laser Therapy (HILT) versus TENS and NSAIDs in low back pain: clinical study. Proc. SPIE 2004; 5610: 277-283 https://doi.org/10.1117/12.584419.

31. Ninomiya $T$, Miyamoto $Y$, Ito $T$, Yamashita $A$, Wakita $M$, Nishisaka $T$. High-intensity pulsed laser irradiation accelerates bone formation in metaphyseal trabecular bone in rat femur. J Bone Miner Metab 2003; 21(2): 67-73. https://doi.org/10.1007/s007740300011.

32. Arisu HD, Türköz E, Bala O. Effects of $\mathrm{Nd}$ :Yag laser irradiation on osteoblast cell cultures. Lasers Med Sci 2006; 21(3):175-180. https://doi.org/10.1007/s10103-006-0398-6.

33. Sarasa-Renedo A, Chiquet M. Mechanical signals regulating extracellular matrix gene expression in fibroblasts. Scand J Med Sci Sports 2005; 15(4): 223-230. https://doi.org/10.1111/j.16000838.2005.00461.x

34. Chiquet M, Renedo AS, Huber F, Flück M. How do fibroblasts translate mechanical signals into changes in extracellular matrix production? Matrix Biol 2003; 22(1): 73-80. https://doi.org/10.1016/s0945053x(03)00004-0.

35. Hawkins $\mathrm{DH}$, Abrahamse $\mathrm{H}$. The role of laser fluence in cell viability, proliferation, and membrane integrity of wounded human skin fibroblasts following helium-neon laser irradiation. Lasers Surg Med 2006; 38(1): 74-83. https://doi.org/10.1002/Ism.20271.

36. AlGhamdi KM, Kumar A, Moussa NA. Low-level laser therapy: a useful technique for enhancing the proliferation of various cultured cells. Lasers Med Sci 2012; 27(1): 237-249. https://doi.org/10.1007/s10103011-0885-2.

37. Ebid AA, Draz AH. Effect of 1064-nm Pulsed High Intensity Nd: YAG Laser on Full Thickness Burn Wound: An Experimental Study. Bull Fac Ph Th Cairo Univ 2010; 15(1): 93-100. http://www.lib.pt.cu.edu.eg/11Amira\%20Jan\%202010.pdf.

38. Ebid AA, Thabet AA, Helal OF. Effect of pulsed high intensity Nd:YAG laser in treatment of chronic diabetic foot ulcer. Energy for Health. Int J Inf Sci Cult 2011; 7: 25-30.

\section{Authors:}

Hesham Galal Mahran - PhD, Assistant Professor, Physical Therapy Department for Surgery, Faculty of Physical Therapy, Cairo University, Giza, Egypt. https://orcid.org/0000-0002-7001-3136. 